\title{
Satisfaction with out of hours primary care
}

\author{
Time to stop writing reports and start taking action
}

\author{
Nicola Walker clinical research fellow, Richard Baker professor
}

Department of Health Sciences, University of Leicester, Leicester LE1 6TP, UK

In November 2014, the House of Commons Committee of Public Accounts concluded that patients' experience of primary care out of hours in England varies considerably and unacceptably across the country, as does the cost. ${ }^{1}$ The committee criticised NHS England for its failure to provide effective oversight and, among other recommendations, urged NHS England to develop its understanding of reasons for the variations in experience and costs. In the July 2014 GP Patient Survey, 66\% of respondents rated their overall experience of out of hours care as "very good" or "good," but the trend is downwards, the respective ratings being 68\% in December 2013 and $71 \%$ in December 2012. ${ }^{2}$

Providing evidence that NHS England will find helpful, a linked paper by Warren and colleagues (doi:10.1136/bmj.h2040) analyses results of the national GP Patient Survey and describes factors associated with poor patient experience of out of hours services. ${ }^{3}$

In recent years various steps have been taken to improve out of hours care. In 2006 the Department of Health published several National Quality Requirements that out of hours providers are obliged to meet. ${ }^{4}$ In 2010, after a series of high profile cases of substandard out of hours care, further recommendations were suggested after a ministerial review. ${ }^{5}$ Since 2012 the Care Quality Commission (CQC) has regulated the quality and safety of out of hours services. An overview of the initial inspections of out of hours care by the CQC identified many examples of good practice but also highlighted areas for improvement. ${ }^{6}$

Over the past decade, out of hours primary care in England has changed substantially. In 2004 an estimated 90\% of GPs opted to transfer responsibility for providing such care to the Primary Care Organisations the NHS had at that time. Today, in areas where GPs have "opted out" of providing out of hours care, most care is provided by social enterprises that are generally not for profit organisations led or run by general practitioners. Common alternative providers include commercial services or other NHS run services such as walk-in centres. For any one individual patient there can be many ways to access care out of hours, which can leave people confused about where to get help.

The NHS 111 number was intended to provide a single entry point for patients needing urgent but not emergency care. It is therefore of particular concern that about a third of adults have either not heard of NHS 111 or have heard of it but do not know what it is for. Not only that, $26 \%$ of people have not heard of out of hours GP services. ${ }^{7}$ To complicate matters, presentations to in hours and out of hours general practice have become more challenging. The growing numbers of older people and those with multimorbidity can often require the assistance of the out of hours service, but they can find it confusing to navigate. They need greater continuity and integration of care during in hours care now more than ever.

Warren and colleagues investigated associations between individual patient characteristics (including ethnicity and the ability to take time away from work to attend a healthcare consultation), the provider of out of hours care (NHS, not for profit, or commercial), and the patient's experience of clinical care (timeliness, confidence and trust in the out of hours clinician, and overall experience of the service). ${ }^{3}$ Commercial provider organisations were associated with reports of poorer patient satisfaction across all three outcomes they investigated. The explanation for this finding is unclear; it is possible that commercial providers are located in areas with more complex population needs, but it is also possible that patient experience is genuinely poorer. If confidence in commercial providers is to be preserved, further work is urgently required to understand the reasons for this finding.

Some ethnic minorities, particularly Asian (defined as Indian, Pakistani, Bangladeshi, other Asian, excluding Chinese, or other ethnic group $)^{8}$ reported a poorer experience, especially when asked about timeliness of care. Poorer experience among ethnic minority groups has also been found for in hours GP care. Although higher expectations and communication issues could partly explain these findings, further qualitative investigation could help to account for potential inequalities in care and finally lead to approaches to delivering care that meet expectations and improve experience. Although more research might be helpful, however, action to change matters should not be delayed any further. In 2008 a Department of Health report concluded that many patients from minority ethnic groups are unable to exert real influence on improving local services and that communication and trust between the local NHS and ethnic minority patients needed urgent improvement. ${ }^{9}$

Warren and colleagues also found that patients in work who were unable to access their own GP reported lower satisfaction 
with out of hours care. ${ }^{3}$ People in work tend to report greater difficulty in accessing their preferred general practitioner in hours, ${ }^{10}$ and proposals have been announced to introduce seven day access to general practices. The practicality of this idea, however, is open to question, as GPs are already struggling to cope with current demand. In a recent survey of GPs conducted by British Medical Association, only $2 \%$ of respondents supported seven day working from their own practices. ${ }^{11}$ The case for bringing practices together into federations or other organisational forms to enable the scheduling of access beyond usual opening hours - as well as to create other efficiencies-is becoming urgent. The GP contract should be reviewed to promote federations. Although we need more research to better understand the experience of some patients and how we should respond, further reports are not needed; it is time for action that makes a real difference.

Competing interests: We have read and understood the BMJ Group policy on declaration of interests and declare the following interests: None.

Provenance and peer review: Commissioned; not externally peer reviewed.

Committee of Public Accounts, House of Commons. Out-of-hours GP service in England Twenty-second Report of Sessions 2014-15. 2014.
2 Ipsos MORI. GP patient survey - national summary report. http://gp-survey-production. s3.amazonaws.com/archive/2014/July/1301375001_Y8W2\%20National\%20Summary\% 20Report_FINAL\%20v1.pdf.

3 Warren FC, Abel G, Lyratzopoulos G, et al. Characteristics of service users and provider organisations associated with experience of out of hours general practitioner care in England: population based cross sectional postal questionnaire survey. BMJ 2015;350:h2040.

4 Department of Health. National quality requirements in the delivery of out-of-hours services. DH, 2006. http://webarchive.nationalarchives.gov.uk/+/www.dh.gov.uk/en/ Publicationsandstatistics/Publications/PublicationsPolicyAndGuidance/DH_4091213.

5 Colin-Thome D, Field S. General practice out-of-hours services: project to consider and assess current arrangements. Department of Health, 2010. http://webarchive. nationalarchives.gov.uk/20130107105354/http://www.dh.gov.uk/en/

Publicationsandstatistics/Publications/PublicationsPolicyAndGuidance/DH 111892.

6 Care Quality Commission. Our new approach to the inspection of NHS GP out-of-hours services: findings from the first comprehensive inspections. CQC, 2014. www.cqc.org.uk/ sites/default/files/20140924_gp_out_of_hours_final.pdf.

7 National Audit Office, Department of Health and NHS England. Out-of hours GP services in England. DH, 2014; 2015.

8 Office for National Statistics. Population estimates by ethnic group: methodology paper. ONS, 2011. www.ons.gov.uk/ons/taxonomy/index.html? nscl=Population+Estimates+by+Ethnic+Group.

9 Lakhani M. No patient left behind: how can we ensure world class primary care for black and minority ethnic people? DH, 2008. www.werconline.org.uk/pdf/left behind.pdf.

10 Baker R, Boulton M, Windridge $\mathrm{K}$, et al. Interpersonal continuity of care: a cross-sectional survey of primary care patients' preferences and their experiences. Br J Gen Pract 2007;57:283-9.

11 British Medical Association. National Survey for GPs. The future of general practice 2015. BMA, 2015. http://bma.org.uk/working-for-change/negotiating-for-the-profession/bmageneral-practitioners-committee/surveys/future-of-general-practice.

Cite this as: BMJ 2015;350:h2185

(C) BMJ Publishing Group Ltd 2015 